\title{
PERSEBARAN ASAL SEKOLAH SISWA SMP NEGERI 1 PADANGAN KABUPATEN BOJONEGORO PRA DAN PASCA ZONASI
}

\author{
M. Zainudin
}

\author{
SMP Negeri 1 Padangan, Bojonegoro
}

\begin{abstract}
Abstrak : SMP Negeri 1 Padangan sebagai bagian dari pendidikan dasar menjadi daya tarik yang cukup tinggi bagi siswa SD di kecamatan Padangan dan sekitarnya baik sebelum pelaksanaan dan setelah pelaksanaan zonasi. Penelitian bertujuan yaitu: (1) mengetahui daerah asal siswa SMP Negeri 1 Padangan sebelum pelaksanaan zonasi, (2) mengetahui daerah asal siswa SMP Negeri 1 Padangan setelah pelaksanaan zonasi, (3) mengetahui pola persebaran asal siswa SMP Negeri 1 Padangan Kabupaten Bojonegoro. Metode penelitian yang digunakan adalah metode deskriptif dengan teknik analisis data sekunder. Analisis data menggunakan teknik analisis data sekunder dan teknik analisis peta. Dengan mentabulasi kedalam bentuk table maupun peta. Hasil penelitian yaitu: (1) Sebelum pelaksanaan zonasi, SMP Negeri 1 Padangan memiliki daerah asal siswa 16 desa dari kecamatan Padangan yaitu desa Padangan 14,7 \%, desa Kuncen 7,8 \% dan desa Dengok 6,3\%. Siswa dari kecamatan lain yaitu kecamatan Kasiman sebesar 9,4 \%, (2) Setelah pelaksanaan zonasi, siswa SMP Negeri 1 Padangan berasal dari 16 desa dari kecamatan Padangan di tahun 2018 dan 11 desa di tahun 2019. Desa Padangan adalah asal desa terbanyak yaitu 10,6 \% di tahun 2018 dan 19,6 \% di tahun 2019 . Asal siswa dari kecamatan lain didominasi dari kecamatan Kasiman, (3) Pola persebaran yang dimiliki SMP Negeri Padangan Kabupaten Bojonegoro yakni berpola mengelompok baik sebelum maupun setelah pelaksanaan zonasi.
\end{abstract}

Kata Kunci : asal siswa, pendidikan, persebaran

Abstract: SMP Negeri 1 Padangan as a part of basic education is a high enough attraction for elementary school students in Padangan sub-district and its surroundings both before the implementation and after the zoning implementation. The research aims are: (1) Knowing the area of origin of students of SMP Negeri 1 Padangan before the implementation of zoning, (2) Knowing the area of origin of students of SMP Negeri 1 Padangan after the implementation of zoning, (3) Analyzing the distribution of the origin of students of SMP Negeri 1 Padangan, Bojonegoro Regency. The research method used is descriptive method with secondary data analysis techniques. Data analysis used secondary data analysis techniques and map analysis techniques. By tabulating it into a table or map form. The results of the study were: (1) Prior to the implementation of zoning, SMP Negeri 1 Padangan had 16 villages from Padangan sub-district, namely Padangan village $14.7 \%$, Kuncen village $7.8 \%$ and Dengok village 6.3\%. Students from other subdistricts, namely Kasiman sub-district, amounted to 9.4\%, (2) After the implementation of zoning, SMP Negeri 1 Padangan students came from 16 villages from Padangan sub-district in 2018 and 11 villages in 2019. Padangan Village is the largest number of villages from which 10,6\% in 2018 and 19.6\% in 2019. The origin of students from other sub-districts is still dominated by Kasiman sub-district, (3) The distribution pattern of SMP Negeri Padangan, Bojonegoro Regency, is a cluster pattern both before and after zoning implementation.

Keywords: student origin, education, distribution

Korespondensi:

e-mail: zainudinm1973@gmail.com 


\section{A. PENDAHULUAN}

Sekolah merupakan lembaga yang memiliki tujuan mulia yang seiring dengan tujuan bangsa Indonesia yaitu mencerdaskan kehidupan bangsa. Cerdas dalam arti tidak hanya cerdas secara keilmuannya tetapi juga cerdas dalam bersosialisasi dengan orang lain dan cerdas mental atau akhlaknya. Pendidikan merupakan faktor penting dalam perkembangan peradaban manusia di dunia, demikian halnya dengan negara Indonesia.

Pendidikan adalah sebuah usaha sadar dan terencana untuk mewujudkan suasana belajar dan proses pembelajaran agar peserta didik secara aktif mengembangkan potensi dirinya untuk memiliki kekuatan spiritual keagamaan, pengendalian diri, kecerdasan, akhlak mulia serta ketrampilan yang diperlukan dirinya, masyarakat, bangsa dan negara (UU No 20 Tahun 2003 ). Oleh karena itu, pendidikan merupakan salah satu faktor penentu dalam peningkatan kualitas sumberdaya manusia. Melalui pendidikan diharapkan perbaikan peradaban manusia dapat disosialisasikan secara tepat, baik melalui penyampaian dan pengembangan ilmu pengetahuan, pengembangan teknologi, pengalaman sosial dan sebagainya. Karena itu, sudah sepatutnya negara Indonesia memiliki perhatian yang besar terhadap pendidikan.
Kecamtan Padangan merupakan daerah yang jauh dari metropolis. Namun demikian fasilitas pendidikannya tidak kalah dengan daerah kota. Jika setiap kecamatan di Kota Metro memiliki seluruh jenis fasilitas pendidikan dasar dengan jumlah yang berbeda-beda ( Ainun N, 20 ), demikian halnya di kecamatan Padangan. Secara geografis, kecamatan Padangan yang memiliki luas $42 \mathrm{~km}$, sebelah utara berbatasan dengan kecamatan Kasiman, sebelah barat dengan kecamatan Cepu, sebelah selatan berbatasan dengan kecamatan Ngraho dan sebelah timur berbatasan dengan kecamatan Purwosari ( BPS Bojonegoro, 2018 ). Masing-masing kecamtan sekitar tersebut memiliki fasilitas pendidikan beragam. Kecamatan Cepu kabupaten Blora provinsi Jawa Tengah memiliki fasilitas pendidikan yang lebih banyak dari pada yang lainnya.

Letak suatu sekolah diharapkan dalam suatu lokasi yang baik atau optimal. Letak suatu sekolah memiliki andil yang besar terhadap kemajuan sekolah tersebut. Lokasi optimal adalah lokasi yang terbaik secara ekonomis (Daldjoeni, 1992). Minimnya biaya transportasi dapat menjadi salah satu pertimbangan dari segi ekonomis. Oleh karena itu jarak sekolah menjadi pertimbangan dalam memilih sekolah. SMP Negeri 1 Padangan memiliki sejarah panjang dalam mendukung negara Indonesia dalam 
mencerdaskan kehidupan bangsa. Sebagai sekolah favorit, tentunya SMP Negeri 1 Padangan telah mengukir nama besar melalui prestasinya, baik di bidang akademik maupun non akademik. Inovasi, perbaikan dan perubahan yang terusmenerus (konstan) menjadi perhatian sekolah dan menjadikannya sebagai lingkaran perbaikan terus-menerus (Husaini Usman, 2006 ). Atas pengalaman yang dimiliki, inovasi yang telah dilakukan maka menjadi modal bagi sekolah untuk meraih prestasi. Hal inilah yang menjadi dasar pijakan para calon orang tua/wali murid dalam memilih SMP Negeri 1 Padangan sebagai pelabuhan pendidikan putra-putrinya. Sejarah sudah terbukti SMP Negeri 1 Padangan tetap menjadi pilihan utama dan menjadi harapan pertama setelah lulus SD / MI khususnya di Kabupaten Bojonegoro Barat .

Berdasar pada latar belakang tersebut diatas, maka rumusan masalah dalam penelitian ini adalah:

1. Dari manakah persebaran asal siswa SMP Negeri 1 Padangan sebelum diterapkannya sistem zonasi.

2. Dari manakah persebaran asal siswa SMP Negeri 1 Padangan setelah diterapkannya sistem zonasi.

3. Bagaimanakah pola persebaran asal siswa SMP Negeri 1 Padangan kabupaten Bojonegoro.

Penelitian ini memiliki manfaat sebagai berikut:
1. Sebagai informasi bagi SMP Negeri 1 Padangan dan masyarakat tentang asal sekolah siswa sebelum pelaksanaan sistem zonasi.

2. Sebagai informasi bagi SMP Negeri 1 Padangan dan masyarakat tentang asal sekolah siswa setelah pelaksanaan sistem zonasi.

3. Sebagai informasi dan pertimbangan bagi SMP Negeri 1 Padangan dan Dinas Pendidikan Kabupaten Bojonegoro dalam melaksanakan kebijakannya.

\section{B. METODE}

Penelitian ini dilakukan di SMP Negeri 1 Padangan Kabupaten Bojonegoro Provinsi Jawa Timur dengan tujuan untuk mengetahui sebaran sekolah asal siswanya. Penelitian ini adalah penelitian deskriptip kualitatif. Analisis deskriptif digunakan untuk memberikan penjelasan kepada variabel yang diteliti sesuai dengan kondisi yang sebenarnya (Arikunto S., 2000).

Penelitian deskriptif adalah penelitian yang dilakukan untuk mengetahui keberadaan variabel mandiri, baik hanya pada satu variabel atau lebih tanpa membuat perbandingan atau menghubungkan dengan variabel lainnya. Variabel mandiri adalah variabel yang berdiri sendiri, bukan variabel independen, karena kalau variabel independen selalu dipasangkan dengan variabel dependen (Sugiyono, 2015). Sebagai penelitian deskriptip, analisis 
deskriptif digunakan untuk memberikan penjelasan kepada variabel yang diteliti sesuai dengan kondisi yang sebenarnya (Arikunto S., 2000 ). Data kuantitatif yang dianalisis sifatnya adalah statistik deskriptif, bukan statistik inferensial. Untuk memperoleh data digunakan teknik triangulasi, yaitu teknik pengumpulan data yang bersifat menggabungkan dari berbagai teknik pengumpulan data dan sumber data yang telah ada. Data primer diperoleh dari kuesioner pendidikan siswa dan guru yang bertujuan untuk mengetahui asal sekolah dan alasan bersekolah di SMP Negeri 1 Padangan. Sedangkan data sekunder diperoleh dari data sekolah setempat dan instansi pemerintah terkait. Grafik, peta dan tabel diperoleh dari hasil analisis data sekunder yang dilakukan melalui tabulasi data. Dari grafik, peta dan tabel yang diperoleh, diberikan penjelasan dengan kalimat.

\section{HASIL DAN PEMBAHASAN}

Tahun 2017 merupakan awal dari penerapan sistem zonasi. Sekolah yang diselenggarakan oleh pemerintah daerah wajib menerima calon peserta didik yang berdomisili pada radius zona terdekat dari sekolah paling sedikit sebesar $90 \%$ dari total jumlah keseluruhan peserta didik yang diterima (Kemendikbud, 2017). Namun pelaksanaannya belum sesuai dengan regulasi yang ada sehingga masih terdapat perbedaan sistem zonasi yang diterapkan di wilayah Kabupaten Bojonegoro. Penerapan zonasi tahun 2017 di Kabupaten Bojonegoro masih memasukkan pertimbangan nilai 3 mata pelajaran Sekolah Dasar yaitu Bahasa Indonesia, Matematika dan Ilmu Pengetahuan Alam.

Salah satu penyebab ketidaksesuaian asal siswa dengan zonasi adalah belum adanya pembatas jarak yang jelas dari pemerintah (Herning Sari Handayani, 2019). Perkembangan beberapa tahun, kebijakan batasan jarak dan penentuan desa dan kecamatan yang masuk zonasi masing-masing SMP Negeri dalam zonasi di Bojonegoro mengalami perubahan. Hal ini dilakukan berdasarkan hasil evaluasi yang tiap tahun dilakukan, yang tentunaya bertujuan untuk lebih baik.

Jumlah siswa SMP Negeri 1 Padangan pada tahun 2017 berdasarkan asal SD/MI sebelum pelaksanaan sistem zonasi diterapkan ditunjukkan pada Tabel 1 dibawah. Asal sekolah siswa SMP Padangan 1 sebelum sistem zonasi didominasi oleh siswa yang berasal dari kecamatan Padangan itu sendiri yaitu 220 siswa atau $70,2 \%$.

Berdasar pada Tabel 1 tersebut juga dapat diketahui asal sekolah siswa yang berasal dari kecamatan lain di sekitar Kecamatan Padangan, yaitu Kecamatan Purwosari, Kecamatan Kasiman, Kecamatan Ngraho, Kecamatan Gayam dan Kecamatan Tambakrejo. Siswa-siswa dari kecamatan lain tersebut bersekolah di SMP Negeri 1 Padangan karena letak 
rumah tinggal mereka secara geografi relatif dekat dengan sekolah. Selain hal tersebut terdapat akses dan sarana transportasi yang memungkinkan siswa tersebut mencapai lokasi SMP Negeri 1 Padangan.

Tabel 1. Asal siswa SMP Negeri 1 Padangan sebelum sistem zonasi

\begin{tabular}{clcc}
\hline No & Nama Desa & $\begin{array}{c}\text { Jumlah } \\
\text { Siswa }\end{array}$ & \% \\
\hline 1 & Padangan & 47 & 14,7 \\
2 & Kuncen & 25 & 7,8 \\
3 & Banjarjo & 18 & 5,6 \\
4 & Dengok & 20 & 6,3 \\
5 & Cendono & 18 & 5,6 \\
6 & Purworejo & 7 & 2,2 \\
7 & Nguken & 17 & 5,3 \\
8 & Ngasinan & 7 & 2,2 \\
9 & Ngradin & 17 & 5,3 \\
10 & Sidorejo & 12 & 3,8 \\
11 & Sonorejo & 4 & 1,3 \\
12 & Kebonagung & 10 & 3,1 \\
13 & Prangi & 6 & 1,9 \\
14 & Tebon & 5 & 1,6 \\
15 & Kendung & 5 & 1,6 \\
16 & Ngeper & 6 & 1,9 \\
17 & Kec. Kasiman & 30 & 9,4 \\
18 & Kec. Gayam & 21 & 6,6 \\
19 & Kec. Purwosari & 25 & 7,8 \\
20 & Kec. Malo & 4 & 1,3 \\
\hline \multicolumn{4}{c}{ Sumber : Hasil Perhitungan }
\end{tabular}

Kecamatan dari provinsi lain yang berdekatan dengan kecamatan Padangan adalah kecamatan Cepu Kabupaten Blora Provinsi Jawa Tengah. Sebanyak 96 siswa yang berasal dari 29 sekolah di kecamatan Padangan sedangkan yang berasal dari luar kecamatan Padangan 29,8\%.
Sebagian besar yang berasal dari luar kecamatan Padangan berasal dari kecamatan Kasiman 9,4\%. Disusul kecamatan Purwosari 7,8\%, kecamatan Gayam 6,6\%.

Persebaran asal siswa SMP Negeri 1 Padangan selanjutnya dapat ketahui melalui peta tematik. Prosentase jumlah siswa yang berasal dari wilayah tersebut dituangkan dalam simbol angka dan piktorial pada peta tersebut. Sebaran asal siswa pada tahun 2017 disajikan pada Gambar 1 di bawah.

Tahun 2018 diterapkan sistem PPDB diterapkan secara murni. Dasar yang digunakan dalam penentuan seleksi penerimaan peserta didik baru adalah jarak terdekat dari lokasi SMP Padangan 1. Jarak yang dimaksud adalah jarak tempat tinggal siswa dengan lokasi sekolah SMP Negeri 1 Padangan. Penerapan sistem zonasi ini dimaksudkan agar siswa yang masuk ke sekolah SMP Negeri di Kabupaten Bojonegoro dapat tersebar secara merata. Sistem ini juga diharapkan agar tidak terjadi penumpukan siswa pada sekolah - sekolah yang dianggap favorit oleh masyarakat .

Jika pada tahun 2017 sistem zonasi penerimaan peserta didik baru masih mempertimbangkan nilai akademik SD/MI maka penerapan sistem zonasi tahun 2018 hanya menitikberatkan pada jarak asal siswa dari sekolah terpilih. Hasil PPDB 2018 merupakan jarak terdekat siswa ke sekolah. 


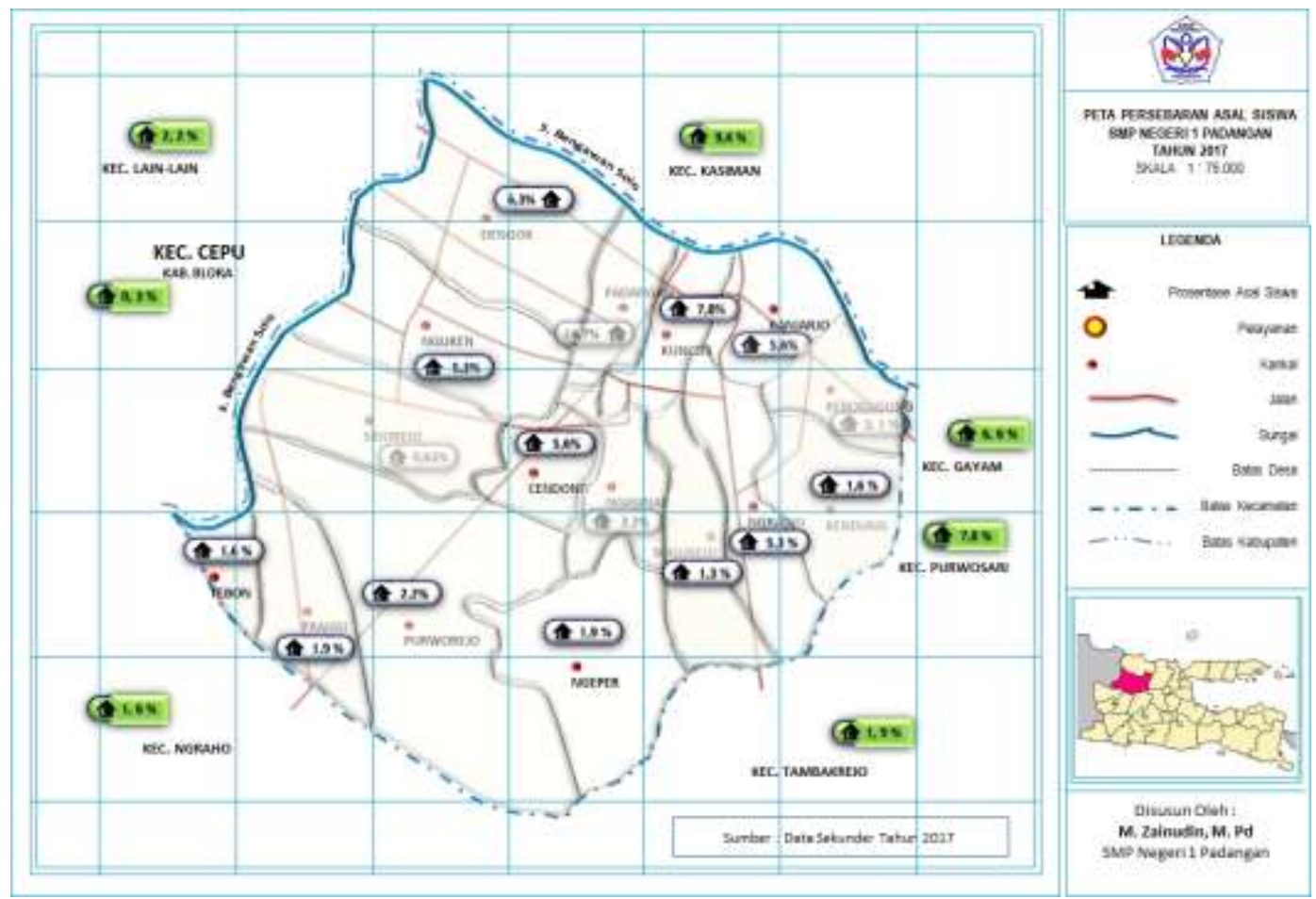

\section{Gambar 1. Peta persebaran asal siswa SMP Negeri 1 Padangan sebelum pelaksanaan sistem zonasi}

Jumlah SD dan MI negeri dan swasta di kecamatan Padangan adalah 29 sekolah/madrasah (BPS Bojonegoro, 2017). Namun asal siswa SMP Negeri 1 Padangan yang berasal dari kecamatan Padangan adalah 15\%. Jumlah siswa tertinggi yang berasal dari desa Padangan sebanyak 245 siswa atau sekitar $10 \%$. Selanjutnya dari desa Kuncen terdapat 20 siswa atau 9\%, dan dari desa Cendono terdapat 21 siswa atau 8,7\%. Sedangkan asal siswa SMP Negeri 1 Padangan Kecamatan Padangan yang paling sedikit berasal dari desa Tebon dan desa Prangi masing-masing sebanyak 3 siswa atau $0,3 \%$. Kedua desa tersebut merupakan desa terluar dari kecamatan Padangan di sebelah selatan dengan jarak tempuh sekitar 3,8 km - 4,3 km. Asal siswa SMP Padangan 1 dari kecamatan lain dalam zonasi sekitar kecamatan Padangan yang masih terjaring adalah kecamatan kasiman 12,8\%. Disusul kecamatan Purwosari $8,7 \%$, kecamatan Gayam 8,3\%, kecamatan Ngraho 2,2\%, kecamatan Tambakrejo 1,3\%, dan dari kecamatan lain $1,9 \%$.

Penerapan sistem zonasi pada tahun 2018 memberikan pengaruh pada sebaran asal siswa SMP N 1 Padangan. Jumlah siswa SMP Negeri 1 Padangan setelah pelaksanaan sistem zonasi tahun 2018 dapat dilihat pada Tabel 2 berikut. 
Tabel 2. Asal siswa SMP Negeri 1 Padangan setelah pelaksanaan sistem zonasi tahun 2018

\begin{tabular}{|c|c|c|c|}
\hline No & Nama Desa & $\begin{array}{c}\text { Jumlah } \\
\text { Siswa }\end{array}$ & $\%$ \\
\hline 1 & Padangan & 33 & 10,6 \\
\hline 2 & Kuncen & 28 & 9,0 \\
\hline 3 & Banjarjo & 12 & 3,8 \\
\hline 4 & Dengok & 10 & 3,2 \\
\hline 5 & Cendono & 27 & 8,7 \\
\hline 6 & Purworejo & 3 & 1,0 \\
\hline 7 & Nguken & 20 & 6,4 \\
\hline 8 & Ngasinan & 12 & 3,8 \\
\hline 9 & Ngradin & 10 & 3,2 \\
\hline 10 & Sidorejo & 10 & 3,2 \\
\hline 11 & Sonorejo & 8 & 2,6 \\
\hline 12 & Kebonagung & 19 & 6,1 \\
\hline 13 & Prangi & 1 & 0,3 \\
\hline 14 & Tebon & 1 & 0,3 \\
\hline 15 & Kendung & 5 & 1,6 \\
\hline 16 & Ngeper & 3 & 1,0 \\
\hline 17 & Kec. Kasiman & 40 & 12,8 \\
\hline 18 & Kec. Gayam & 26 & 8,3 \\
\hline 19 & Kec. Purwosari & 27 & 8,7 \\
\hline 20 & Kec. Malo & 5 & 1,6 \\
\hline 21 & Kec. Tambakrejo & 4 & 1,3 \\
\hline 22 & Kec. Ngraho & 7 & 2,2 \\
\hline 23 & Kec. Margomulyo & 1 & 0,3 \\
\hline
\end{tabular}

Sebagai pendukung asal siswa SMP Negeri 1 Padangan tahun 2018 yang telah secara murni dalam penerapan sistem zonasi maka perlu juga diketengahkan asal siswa pada tahun 2019. Sama halnya dengan tahun 2018, pelaksanaan sistem zonasi tahun 2019 menitik beratkan pada jarak asal siswa dengan sekolah yang dipilih sehingga hasil siswa yang diterima adalah jarak terdekat asal siswa dengan
SMP Negeri 1 Padangan. Jumlah siswa yang diterima adalah 320 siswa, walaupun dalam perkembangannya ada 1 anak yang mengundurkan diri. Berikut adalah data asal sekolah siswa SMP Negeri 1 Padangan tahun 2019.

Tabel 3. Asal siswa SMP Negeri 1 Padangan setelah pelaksanaan sistem zonasi tahun 2019

\begin{tabular}{clcc}
\hline No. & Nama Desa & $\begin{array}{c}\text { Jumlah } \\
\text { Siswa }\end{array}$ & $\begin{array}{c}\text { Prosentase } \\
(\%)\end{array}$ \\
\hline 1 & Padangan & 61 & 19,12 \\
2 & Kuncen & 40 & 12,54 \\
3 & Banjarjo & 29 & 9,09 \\
4 & Dengok & 45 & 14,11 \\
5 & Cendono & 30 & 9,40 \\
6 & Purworejo & 8 & 2,51 \\
7 & Nguken & 21 & 6,58 \\
8 & Ngasinan & 5 & 1,57 \\
9 & Ngradin & 11 & 3,45 \\
10 & Sidorejo & 23 & 7,21 \\
11 & Sonorejo & 4 & 1,25 \\
12 & Kebonagung & 12 & 3,76 \\
13 & Kec. Kasiman & 29 & 9,09 \\
14 & Kec. Gayam & 1 & 0,31 \\
\hline \multicolumn{4}{c}{ Sumber : Hasil Perhitungan }
\end{tabular}

Berdasar Tabel 2 dan Tabel 3 dapat dilihat bahwa terjadi variansi asal siswa SMP Negeri 1 Padangan. Tabel 3 menunjukkan hanya terdapat 14 lokasi asal siswa di tahun 2019 dari yang sebelumnya sebanyak 23 lokasi di tahun 2018. Data tersebut menjelaskan bahwa sistem zonasi memberikan pengaruh terhadap sebaran lokasi asal siswa SMP N 1 Padangan. Sebaran asal siswa SMP Negeri 1 Padangan setelah pelaksanaan zonasi tahun 2019 disajikan pada Gambar 2 berikut. 


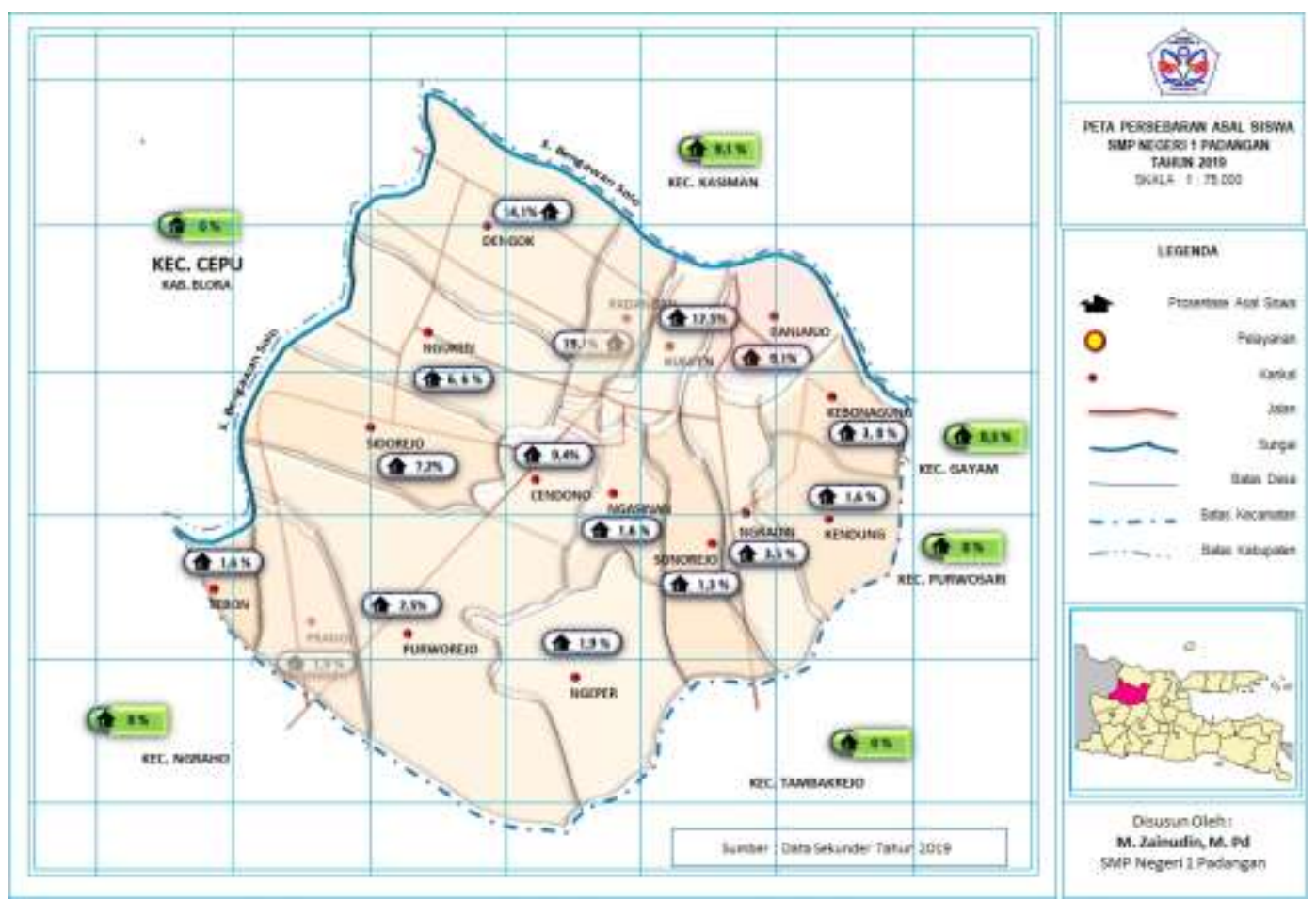

Gambar 2. Peta persebaran asal siswa SMP Negeri 1 Padangan setelah pelaksanaan sistem zonasi tahun 2019

Gambar 2 menunjukkan proporsi sebaran jumlah asal siswa yang bersekolah di SMP N 1 Padangan. Siswa yang berasal dari luar kecamatan nampak jauh berkurang pada penerimaan tahun 2019. Asal sekolah siswa SMP Negeri 1 Padangan yang berasal dari kecamatan Padangan yaitu 319 siswa atau $99 \%$. Jumlah terbanyak berasal dari desa Padangan. Asal sekolah siswa dari desa Padangan adalah yang terbanyak, yaitu 61 siswa atau sekitar 19,1\%. Selanjutnya dari desa Dengok 45 siswa atau 14,1\%, desa Kuncen sebanya 40 siswa atau 12,5 $\%$, dari desa Banjarjo 29 siswa, dan dari desa Cendono sebanyak 30 siswa atau 9,4 $\%$. Sedangkan asal sekolah siswa SMP
Negeri 1 Padangan dari kecamatan Padangan yang paling sedikit adalah dari desa Sonorejo 4 siswa atau 1,3\%. Hal ini dikaenakan kedua desa tersebut adalah desa terluar dari kecamatan Padangan di sebelah selatan dengan jarak sekitar 3,8 $\mathrm{km}-4,3 \mathrm{~km}$. Asal sekolah siswa SMP Negeri 1 Padangan dari kecamatan lain dalam zonasi di sekitar kecamatan Padangan yang masih terjaring adalah kecamatan Kasiman 29 siswa atau 9,1\% dan kecamatan Gayam 1 siswa atau 0,3\%. Asal siswa dari kecamatan Kasiman cukup banyak karena akses transportasi sangat mudah dengan adanya jembatan penghubung dan jaraknya sekitar 1- 2 kilometer. 


\section{KESIMPULAN}

1. Asal siswa di SMP Negeri 1 Padangan Kabupaten Bojonegoro sebelum penerapan zonasi berasal dari 16 desa, terbanyak adalah dari desa Padangan $14,7 \%$, desa Kuncen 7,8 \% dan Dengok $6,3 \%$. Ketiga desa tersebut berada di Kecamatan Padangan dengan jarak dari SMP Negeri 1 Padangan sekitar $0-1$ kilo meter. Sedangkan asal siswa dari luar kecamatan Padangan terbanyak adalah dari kecamatan Kasiman dengan jarak sekitar 0 - $1 \mathrm{~km}$. Tahun Pelajaran 2017/2018 telah diterapkan sistem zonasi tetapi masih memperhitungkan nilai bahasa Indonesia, Matematika dan IPA sehingga dalam penelitian ini dianggap belum melaksanakan zonasi secara murni.

2. Asal siswa SMP Negeri 1 Padangan setelah penerapan zonasi yaitu tahun 2018 terdiri dari 16 desa dan didominasi siswa dari desa Padangan, yaitu $10 \%$. Prosentase asal siswa dari desa Padangan menurun dibandingkan dengan tahun 2017, yaitu 14,7\%. Selanjutnya dari desa Kuncen yang meningkat dari tahun 2017 sejumlah 7,8 \% menjadi 9,0 \% ditahun 2018 . Desa Cendono menjadi peringkat ketiga asal siswa SMP Negeri 1 Padangan setelah desa Kuncen, yaitu $8,7 \%$. Asal siswa dari Desa padangan dan desa Kuncen menjadi terbanyak karena kedua desa tersebut merupakan desa terdekat dari SMP Negeri 1 Padangan. Selanjutnya desa Cendono dengan jarak sekitar 1-2 km dari SMP Negeri 1 Padangan yang menjadi asal siswa terbanyak ketiga, yaitu $8,7 \%$. Untuk kecamatan lain dalm zonasi yang asal siswanya terbesar masih seperti tahun 2017, yaitu kecamatan Kasiman dengan prosentase $12,8 \%$. Untuk tahun 2019, asal siswa SMP Negeri 1 Padangan dari 11 desa dan terbanyak berasal kecamatan Padangan, yaitu dari desa Padangan sebesar $19,6 \%$. Terjadi peningkatan dibandingkan dengan tahun 2018, yang hanya $10,6 \%$. Urutan kedua berasal dari desa Dengok, yaitu 14,1\% dengan jaraj $0-1 \mathrm{~km}$. Selanjutnya asal siswa dari desa Kuncen menempati urutan ketiga, yaitu 12, $5 \%$. Asal siswa daari desa Kuncen mengalami penurunan dibandingkan dengan sebelum pelaksanaan zonasi dan zonasi tahun 2018 yang sebelumnya menempati urutan kedua. Sedangkan asal siswa SMP Negeri 1 Padangan dari kecamatan lain dalam zonasi adalah 2 kecamatan dan masih didominasi dari kecamatan Kasiman, $9,1 \%$.

3. Berdasarkan analisis tetangga terdekat maka dapat disimpulkan bahwa pola persebaran asal siswa SMP Negeri 1 Padangan sebelum dan setelah pelaksanaan zonasi adalah mengelompok. 


\section{DAFTAR PUSTAKA}

Ainun, Nurma. (2018). Analisis Ketersediaan dan Keterjangkauan Fasilitas Pendidikan Jenjang Sekolah Dasar (SD) dan Sekolah Menengah Pertama (SMP) di Kota Metro. Skripsi. Fakultas Geografi. Universitas Gadjah Mada: Yogyakarta.

Arikunto, S. 2000. Prosedur Penelitian Suatu Pendekatan Praktek. Jakarta: Rineka Cipta

Badan Pusat Statistik. (2017). Kecamatan Padangan Dalam Angka Tahun 2017.. Kabupaten Bojonegoro.

Badan Pusat Statistik. (2018). Kecamatan Padangan Dalam Angka Tahun 2018. Kabupaten Bojonegoro.

Badan Standarisasi Nasional. (2004). Standar Nasional Indonesia. Jakarta: Badan Standar Nasional.

Daldjoeni, N. 1992. Seluk Beluk Masyarakat Kota. Bandung: Penerbit Alumni.

Herning Sari Handayani. (2019). Analisis Kesesuaian Persebaran Daerah Asal Siswa Dengan Zonasi Sekolah Menengah Atas Di Kabupaten Karanganyar. Skripsi. Fakultas Geografi. Universitas Muhamadiyah Surakarta: Surakarta.

Husaeni Usman. (2006). Manajemen: Teori, Praktik, dan Riset Pendidikan. Jakarta: Bumi Aksara. Peraturan Menteri Pendidikan Dan Kebudayaan RI No. 17 tahun 2017 tentang Penerimaan Peserta Didik
Baru. (Jakarta: Kemendikbud, 2017).

Sugiyono. (2008). Metode Penelitian Pendidikan. Bandung: CV Alfabeta.

Sugiyono. (2015). Metode Penelitian Kombinasi (Mix Methods). Bandung: CV Alfabeta. Undang-Undang Nomor 20 Tahun 2003 Tentang Sistem Pendidikan Nasional. 